\title{
Retrospective cohort study of the efficacy of caprylic triglyceride in patients with mild-to-moderate Alzheimer's disease
}

This article was published in the following Dove Press journal:

Neuropsychiatric Disease and Treatment

22 October 2013

Number of times this article has been viewed

\author{
Steven Douglas Maynard ${ }^{1,2}$ \\ Jeff Gelblum ${ }^{3}$ \\ 'Union Associated Physicians Clinic, \\ ${ }^{2}$ Indiana University School of \\ Medicine, Terre Haute, IN, ${ }^{3}$ Mt Sinai \\ Medical Center of Miami, Aventura \\ Hospital, Aventura, FL, USA
}

Background: The purpose of this study was to evaluate the effects of caprylic triglyceride (CT) in patients with mild-to-moderate Alzheimer's disease (AD) in routine clinical practice via review of medical records and caregiver questionnaires.

Methods: Participants were outpatients aged $\geq 50$ years with a diagnosis of probable mild-tomoderate $\mathrm{AD}$ who had received $\mathrm{CT}$ for $\geq 6$ months. The primary outcome was change from baseline in the patient's condition as rated by the treating physician using a physician's overall assessment.

Results: A total of 55 patients were included. The physician's overall assessment indicated that $\sim 80 \%$ of patients who had CT added to ongoing pharmacotherapy were stable or improved. Mini-Mental State Examination scores also remained stable over 15 months of therapy $(20.6 \pm 3.0$ at baseline and $20.1 \pm 5.6$ at follow-up, $P=0.5233, \mathrm{n}=27$ ). Caregiver assessments indicated that most patients were stable or improved with respect to memory and ability to carry out activities of daily living. The most frequent adverse events with CT involved the gastrointestinal system.

Conclusion: Results from this chart review indicate that addition of CT to pharmacotherapy was associated with stable disease or improvement over a follow-up period of 18.8 months.

Keywords: ketosis, cognition, Alzheimer's disease, metabolism, caprylic triglyceride

\section{Introduction}

Alzheimer's disease (AD) is the most common neurologic condition affecting the elderly in the US. The cost associated with AD is currently high and is expected to grow over the next 40 years. Total payments in 2012 for health care and long-term care services for people with AD and other dementias are expected to be $\$ 200$ billion (not including the contributions of unpaid caregivers). ${ }^{1}$ The cost of care for AD in the US is expected to rise above $\$ 1$ trillion by $2050 .^{2}$

Pharmacologic strategies for the treatment of $\mathrm{AD}$ have focused on modulating disease-associated neurotransmitter alterations. ${ }^{3}$ Two classes of pharmacologic agents approved for treatment of AD are cholinesterase inhibitors and an N-methyl-D-aspartate receptor antagonist. ${ }^{3-5}$ These agents are considered symptomatic treatments based on their ability to slow the clinical progression of symptoms across cognitive, behavioral, and functional domains. They do not provide detectable and sustained improvements in cognitive function above baseline. ${ }^{3-5}$ New therapies are needed.

The brains of patients with AD display progressive, region-specific declines in the cerebral metabolic rate of glucose, ${ }^{6}$ and these changes are apparent early in the course of $\mathrm{AD}$ before there is demonstrable cell loss and plaque deposition.?
Correspondence: Steven Douglas Maynard

Union Associated Physicians Clinic, Indiana University School of Medicine, I739 N 4th Street, Terre Haute, IN 47804, USA

Tel + I 8122423125

Fax +18122423446

Email stevendmay2002@yahoo.com 
Under most conditions, cerebral metabolism is fueled almost exclusively by glucose. However, under certain conditions, such as neonatal development and extended fasting, the brain will derive much of its energy from ketone bodies. ${ }^{8,9}$ Ketone bodies are comprised of beta-hydroxybutyrate, acetoacetate, and acetone. They are normally derived from fat stores and offer an alternative fuel for brain metabolism. Therefore, if cerebral glucose metabolism is compromised in the AD patient, perhaps ketone bodies can substitute for glucose and improve cognitive performance. ${ }^{9,10}$ Ketone bodies are an efficient fuel for cells, ${ }^{11,12}$ and results from preclinical studies have suggested that induced ketosis may be beneficial in AD. ${ }^{13,14}$ In addition, studies have suggested that ketone bodies may be useful in a variety of neurologic disorders. ${ }^{15}$

A previous study has demonstrated that administration of $20 \mathrm{~g}$ of caprylic triglyceride (CT) increases blood levels of beta-hydroxybutyrate (the major ketone body in humans) 2 hours post dose to a mean value of $0.39 \mathrm{mM}$, and this therapy has been shown to be beneficial in patients with mildto-moderate $\mathrm{AD} \cdot{ }^{10,16} \mathrm{CT}$ is composed of a glycerol backbone and three caprylic (C8:0) fatty acid chains, well known for their ketogenic properties. ${ }^{17}$ The efficacy and safety of a medical food containing $\mathrm{CT}$ in subjects with mild-to-moderate AD has been demonstrated in a multicenter, randomized, doubleblind, placebo-controlled study that included 152 outpatients with probable mild-to-moderate AD. ${ }^{10}$

It is important to continue evaluations of interventions in routine clinical practice. This approach has been taken with pharmacotherapies for AD, ${ }^{18-20}$ and CT should be evaluated in a similar manner. The primary objective of this study was to assess patient outcomes of CT used alone or in combination with ongoing pharmacotherapy in mild-to-moderate $\mathrm{AD}$ in routine clinical practice. Due to the small number of patients enrolled in the study, the results should be considered exploratory.

\section{Materials and methods Study design}

Patient outcomes were evaluated by chart review carried out at 11 practices in which CT was prescribed in patients with mild-to-moderate AD. Investigators at each site were instructed to review all charts for patients who were taking or had taken CT and determine their eligibility for the study. The criteria for inclusion were male or female outpatients aged $\geq 50$ years with a diagnosis of probable AD of mild-to-moderate severity; Mini-Mental State Examination
(MMSE) score between 14 and 24 inclusive at the initiation of CT (if available), or diagnosis of mild-to-moderate AD; and receipt of CT for $\geq 6$ months. Potential patients were excluded if they had an MMSE score $<14$ at the time when CT was initiated or comorbid disease known to adversely impact cognitive function (eg, Parkinson's disease, history of cerebral infarcts, dementia with Lewy bodies, vascular dementia). Approximately 200 patients were to be enrolled in the study. The sample size was based on estimates of numbers of patients who were available for inclusion as reported by participating physicians, and not based on any statistical considerations. After an independent evaluation of potential patients, only 55 were found to be eligible for participation. The trial was carried out with institutional review board approval. Patients and caregivers were required to provide written informed consent prior to inclusion of their information in the study. This study is registered at http://www. clinicaltrials.gov/ct2/show/NCT01538212.

A caregiver was defined to be at least 21 years of age (this age was believed to be appropriate for a caregiver who would provide a patient assessment as part of the study), had been the primary caregiver since prior to the initiation of CT, provided at least 4 hours of supervision or direct assistance per day for the patient, and was able to perform assessments.

\section{Assessments}

Two primary measures were used to assess the patient's response to CT. The first was the physician's overall assessment of patient status at the most recent evaluation on CT. The second was the change in MMSE score from initiation of CT to the most recent MMSE assessment on CT. The physician's overall assessment of patient status comprised three simple evaluations. First, status at initiation of CT therapy, scored as check boxes of: mild AD or moderate AD. Second, status at most recent evaluation, scored as check boxes of: mild $\mathrm{AD}$, moderate $\mathrm{AD}$, severe $\mathrm{AD}$, very severe AD. Third, change from beginning of CT to present, scored as check boxes of: marked improvement, moderate improvement, improvement, stable, worsening, moderate worsening, or marked worsening.

Secondary measures included changes from baseline in patient's living situation; medication changes for the management of AD and for psychiatric symptoms related to AD; changes in patient's memory and ability to carry out instrumental activities of daily living as assessed by caregivers; and adverse events. Caregiver questionnaires 
were also employed to determine CT dosing frequency (number of days per week); to estimate routine dose level (full dose or less than a full dose is generally taken); and adherence to $\mathrm{CT}$ (if available). Caregivers were also asked to assess the patient's memory since initiation of CT, based on a modified version of the Memory Complaints Questionnaire developed by Memory Assessment Clinics; and ability to carry out activities of daily living adapted from Lawton and Brody. ${ }^{21}$

\section{Data analysis}

Scores from the physician's overall assessment of change from baseline after initiation of $\mathrm{CT}$ were summarized with descriptive statistics. The primary analysis of the MMSE was a paired $t$-test of baseline score and last available score while on CT. Changes from baseline in caregiver assessments of patients' ability to use the telephone, prepare food, and dress were evaluated with Mann-Whitney $U$-tests. All statistical tests were two-sided and were carried out at the 5\% level of significance. Results for all demographic and secondary study endpoints were tabulated and appropriate descriptive statistics were calculated. Pearson correlation between physician's overall assessment of change and caregiver assessment was performed with R 2.15.0 (www.r-project.org).

\section{Results \\ Records reviewed}

A total of 437 records were reviewed at 11 study sites, and those of 55 patients who met the inclusion and exclusion criteria and provided informed written consent were included in the analysis. The most common reasons for exclusion were MMSE scores out of the designated inclusion range, taking $\mathrm{CT}$ for $<6$ months, no formal diagnosis of AD, and comorbidities that may have affected cognitive function. Caregiver questionnaires were filled out for a total of 26 patients. A minimum of 28 hours of caregiving per week was set as a criterion for inclusion in the study protocol. Five caregivers did not meet this minimum, and were not included in the analysis.

The demographic and clinical characteristics of the patients whose records were analyzed are summarized in Table 1 . Nearly all patients (96.4\%) were receiving medications indicated for the treatment of $\mathrm{AD}$; and $54.6 \%$ were receiving agents indicated for other psychiatric symptoms (most often depression). At baseline, $88.7 \%$ of patients were living with caregivers (relatives) and $11.3 \%$ were residing in assisted living facilities.
Table I Demographic and clinical characteristics of patients whose records were reviewed

\begin{tabular}{|c|c|}
\hline Characteristic & $\mathbf{N}=\mathbf{5 5}$ \\
\hline \multicolumn{2}{|l|}{ Sex, n (\%) } \\
\hline Male & $31(56.4)$ \\
\hline Female & $24(43.6)$ \\
\hline Age, years (mean $\pm S D)$ & $79.7 \pm 7.46$ \\
\hline $\begin{array}{l}\text { Duration of disease since formal diagnosis, years } \\
\text { (mean } \pm \text { SD) }\end{array}$ & $3.0 \pm 1.96$ \\
\hline \multicolumn{2}{|l|}{ Basis of $A D$ diagnosis, $n(\%)$} \\
\hline Signs and symptoms & $55(100)$ \\
\hline Computed tomography & $14(25.4)$ \\
\hline Magnetic resonance imaging & $21(38.2)$ \\
\hline Cognitive testing & $50(90.9)$ \\
\hline Electroencephalography & $9(16.4)$ \\
\hline \multicolumn{2}{|l|}{ Disease severity at baseline, $n(\%)$} \\
\hline Mild & $24(43.6)$ \\
\hline Moderate & $31(56.4)$ \\
\hline \multicolumn{2}{|l|}{ AD treatment at baseline, $n(\%) *$} \\
\hline Memantine & $48(87.3)$ \\
\hline Donepezil & $24(43.6)$ \\
\hline Rivastigmine patch & $18(32.7)$ \\
\hline Galantamine & $3(5.4)$ \\
\hline None & $2(3.6)$ \\
\hline Mean duration of $\mathrm{CT}$ in months \pm SD (range) & $18.8 \pm 9.2(6-39)$ \\
\hline \multicolumn{2}{|l|}{ Living arrangement, n (\%) } \\
\hline With caregiver & $47(88.7)$ \\
\hline Assisted living facility & $6(11.3)$ \\
\hline \multicolumn{2}{|l|}{$\begin{array}{l}\text { Concomitant medications for neuropsychiatric } \\
\text { conditions, } \mathrm{n}(\%)^{* *}\end{array}$} \\
\hline Escitalopram & $8(14.5)$ \\
\hline Citalopram & $7(12.7)$ \\
\hline Duloxetine & $5(9.1)$ \\
\hline Alprazolam & $5(9.1)$ \\
\hline Bupropion & $4(7.3)$ \\
\hline Quetiapine & $4(7.3)$ \\
\hline Dextromethorphan & $3(5.4)$ \\
\hline Venlafaxine & $3(5.4)$ \\
\hline Mirtazapine & $2(3.6)$ \\
\hline Sertraline & $2(3.6)$ \\
\hline Aripiprazole & $\mathrm{I}(1.8)$ \\
\hline Valproate & $\mathrm{I}(\mathrm{I} .8)$ \\
\hline Modafinil & $\mathrm{I}(\mathrm{I} .8)$ \\
\hline Amphetamine & $\mathrm{I}(\mathrm{I} .8)$ \\
\hline Lamotrigine & $\mathrm{I}(\mathrm{I} .8)$ \\
\hline Desvenlafaxine & $\mathrm{I}(\mathrm{I} .8)$ \\
\hline Ziprasidone & $\mathrm{I}(\mathrm{I} .8)$ \\
\hline None & $25(45.5)$ \\
\hline
\end{tabular}

Notes: *Multiple evaluations were possible; **patients may have been taking more than one medication.

Abbreviations: $A D$, Alzheimer's disease; $C T$, caprylic triglyceride; $S D$, standard deviation.

\section{CT dosing}

Patients who had received CT, regardless of the dose, for 6 months or longer were eligible for the study. For the 55 patients whose records were reviewed, the mean duration 
of CT was $18.8 \pm 9.2$ months. Chart review indicated that most patients $(89.1 \%)$ were titrated to a full $20 \mathrm{~g}$ daily CT dose. The remainder (10.9\%) received $10 \mathrm{~g}$ per day.

\section{Patient outcomes}

\section{Primary measures}

Physician's overall assessment of changes from baseline in patient status (Figure 1A) were marked improvement for $5.5 \%$, moderate improvement for $5.5 \%$, improvement for $24.1 \%$, stable for $44.4 \%$, worsening for $14.8 \%$, moderate worsening for $3.7 \%$, and marked worsening for $1.8 \%$. MMSE scores at baseline and while on CT were available for 27 patients. The mean baseline score for these patients was $20.6 \pm 3.0$ and that for the most recent measurement on CT was $20.1 \pm 5.6$ (difference -0.48 , 95\% confidence interval -1.05 to $2.01, t=0.6470, P=0.5233)$.

\section{Secondary measures}

At baseline, $43.6 \%$ of patients were rated by their physicians as having mild AD and 56.4\% were considered to have moderate $\mathrm{AD}$. Of the 55 participants, $80 \%(\mathrm{n}=44)$ did not change in severity of disease, while $20 \%(n=11)$ were diagnosed with a more advanced disease state (Figure 1B).

No patients whose records were reviewed had changes in their living situation during CT therapy. There were also few changes in medications patients were taking for $\mathrm{AD}$; $87.3 \%$ of patients had no changes; $7.3 \%$ had switches or augmentation in pharmacotherapy, and 5.4\% had addition of a medical food that included phosphatidylserine enriched with docosahexaenoic acid. Pharmacotherapy for psychiatric/behavioral symptoms also remained stable for most patients $(70.9 \%)$. There were 25 patients taking no medications for psychiatric illness at baseline and six of these $(10.9 \%$ of all patients, $24.0 \%$ of those not taking psychiatric medications at baseline) had agents added to therapy, most often antidepressants or atypical antipsychotics. In addition, $33.0 \%$ of patients receiving medications at baseline had switches and/or additions to their therapy. These changes most often included switching and/or augmentation of antidepressant treatment and addition of an anxiolytic.

\section{Results from caregiver surveys}

Caregivers' responses indicated that addition of CT to therapy resulted in some degree of improvement or stability in remembering the name of a person to whom they were just introduced in $80.9 \%(17 / 21)$ of patients, recalling telephone numbers or zip codes that were used on a daily or weekly basis in $80.9 \%(17 / 21)$, and in finding commonly used objects in $85.7 \%(18 / 21)$, as shown in Figure 2. Overall assessments of memory also indicated that the majority of patients $(75.0 \%)$ $(15 / 20)$ were stable or improved over the follow-up period (Figure 2). Assessment of ability to use the telephone, prepare food, and dressing indicated no significant changes from baseline (Mann-Whitney $U$-tests, $P=0.696, P=0.904$, and $P=0.596$, respectively).

\section{Correlation between physician and caregiver assessments}

Caregivers and physicians may assess a change in patient status differently. However, a significant correlation was found between the physician's overall assessment of change and caregiver surveys $(r=-0.5423$, confidence interval -0.80 to $-0.12, P=0.016$, Figure 3 ).

\section{Safety outcomes}

Of the 55 patients whose charts were reviewed, 41 (74.5\%) had no adverse events. The remaining 14 patients had a
A

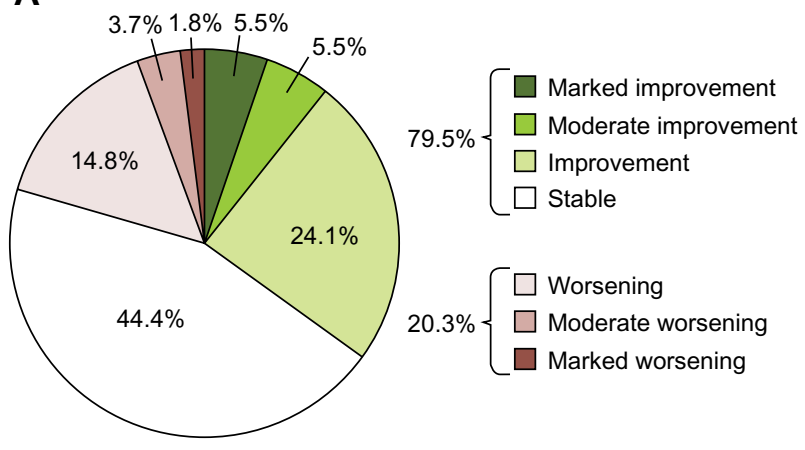

B

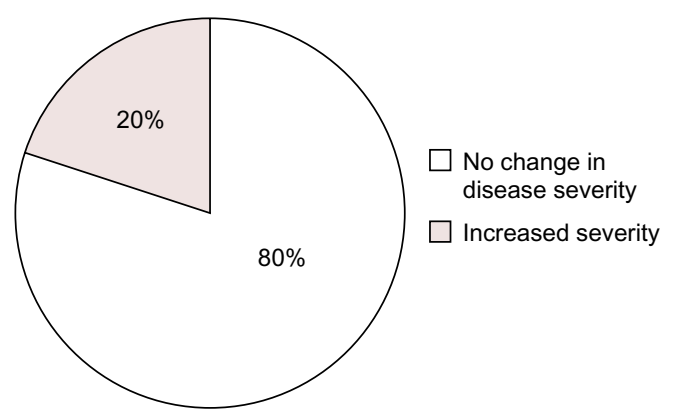

Figure I Physician's overall assessment of change from baseline. (A) Pie chart depicting overall change in patients. Green shading indicates improvement, red shading indicates worsening, and white represents stable status. (B) Percent of patients with change in severity of disease compared with initiation of caprylic triglyceride (CT). Mean duration of therapy 18.8 months. 


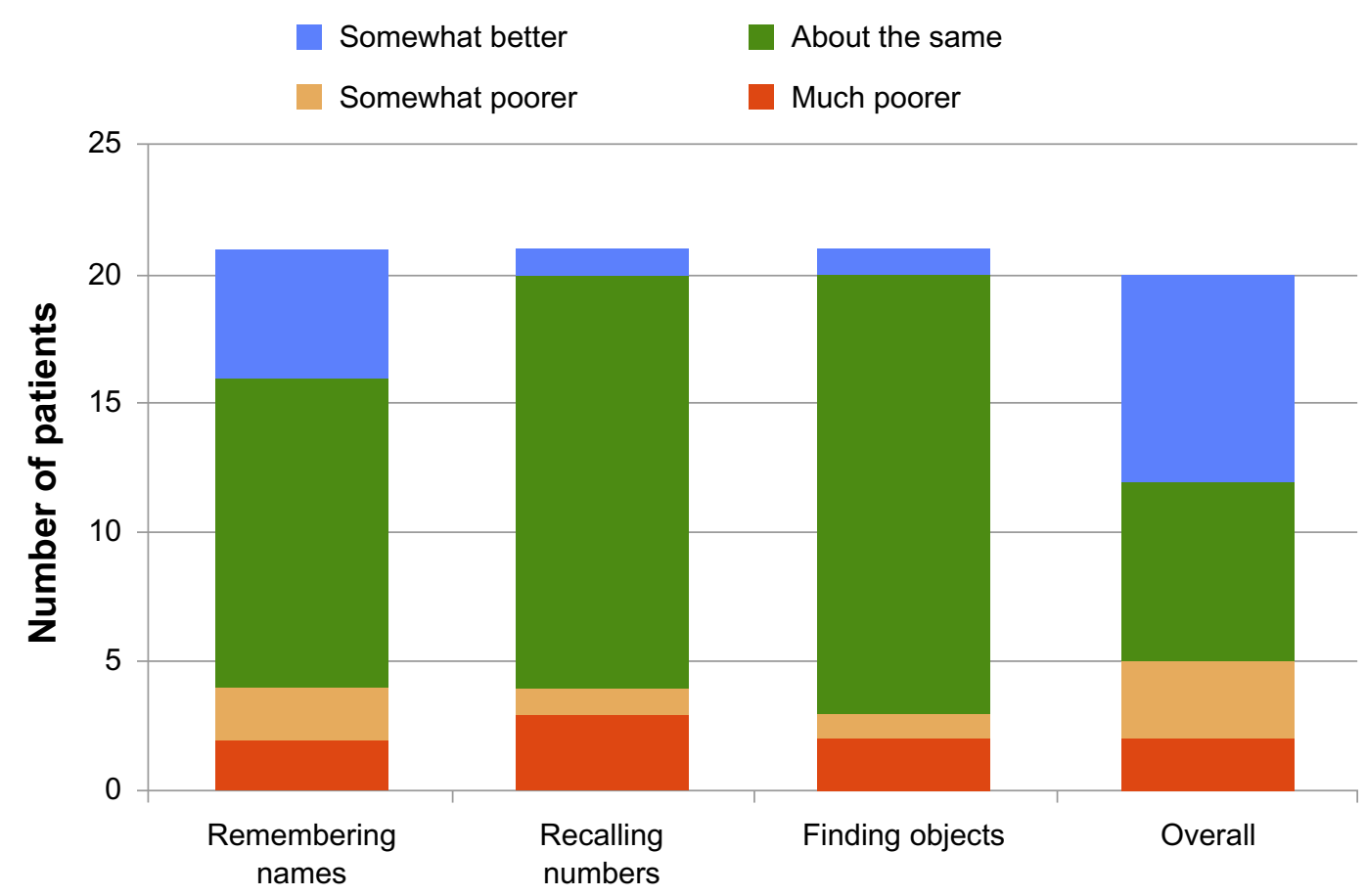

Figure 2 Caregiver assessment of memory function.

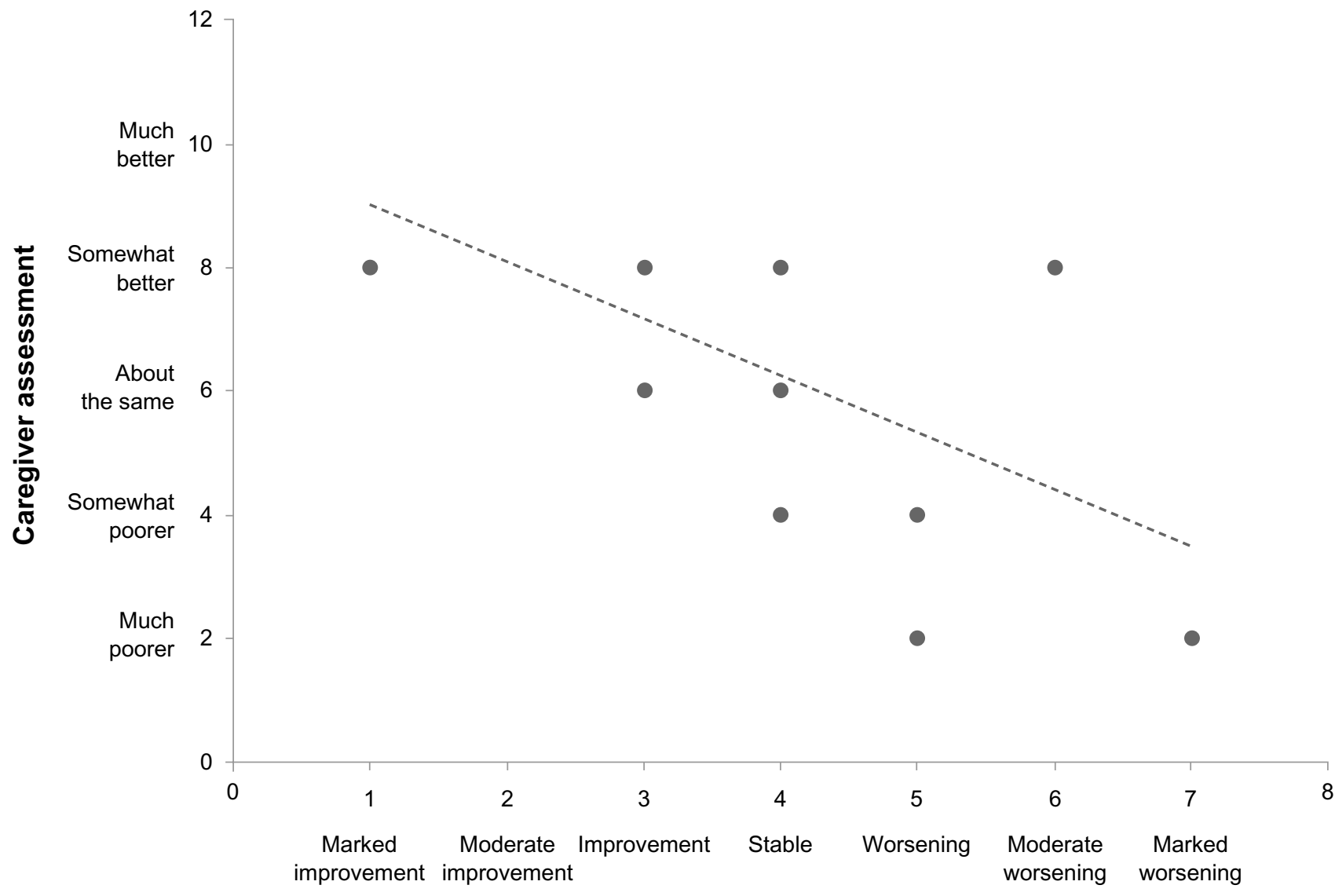

Physician assessment

Figure 3 Correlation of results between physician and caregiver assessments. 
total of 30 adverse events, eight of which were considered to be related to $\mathrm{CT}$. All related adverse events involved the gastrointestinal system. There was one severe adverse event, a brain tumor that was not related to CT. A total of eight patients $(14.5 \%)$ discontinued CT and four of these $(7.3 \%)$ discontinued due to adverse events. All adverse events are summarized in Table 2.

\section{Discussion}

Results from this chart review suggest that CT helped to stabilize or improve the clinical status and cognitive function in patients receiving therapy for a mean of approximately 19 months. The physician's overall assessment of change from baseline indicated that $79.5 \%$ of patients either showed improvement or remained stable, while $20.3 \%$ worsened. Results for the 27 patients for whom MMSE scores were available at baseline and on therapy indicate that, on average, patients remained stable with no significant change over a mean of 15 months of follow-up. No patients had changes in their living situation during CT therapy, and most patients remained stable with respect to medications for $\mathrm{AD}$ and those for psychiatric/behavioral conditions. The adverse event most often associated with CT was mild gastrointestinal upset. Caregiver assessments also indicated stability or improvement in cognitive function and no significant changes in

Table 2 Adverse events

\begin{tabular}{ll}
\hline Adverse event & $\mathbf{N}=\mathbf{5 5}$ \\
& $\%$ \\
\hline Gastrointestinal upset & $\mathrm{I} 4.5$ \\
Diarrhea & $\mathrm{I} .8$ \\
Lightheadedness & $\mathrm{I} .8$ \\
Dizziness & $\mathrm{I} .8$ \\
Irritable bowel syndrome & $\mathrm{I} .8$ \\
Disturbed balance & $\mathrm{I} .8$ \\
Disturbed vision & $\mathrm{I} .8$ \\
Impaired consciousness & $\mathrm{I} .8$ \\
Slurred speech & $\mathrm{I} .8$ \\
Fatigue & $\mathrm{I} .8$ \\
Leg cramp & $\mathrm{I} .8$ \\
Confusion & $\mathrm{I} .8$ \\
Urinary frequency & $\mathrm{I} .8$ \\
Brain tumor & $\mathrm{I} .8$ \\
Agitation & $\mathrm{I} .8$ \\
Pernicious anemia & $\mathrm{I} .8$ \\
Ankle pain & $\mathrm{I} .8$ \\
Weight loss & $\mathrm{I} .8$ \\
Upper respiratory infection & $\mathrm{I} .8$ \\
Fall with hip fracture & $\mathrm{I} .8$ \\
Hypervitaminosis (BI2) & $\mathrm{I} .8$ \\
Hospitalization (failure to eat) & $\mathrm{I} .8$ \\
Headache & $\mathrm{I} .8$ \\
\hline & \\
\hline
\end{tabular}

the ability to carry out activities of daily living. There was a significant correlation between physician and caregiver assessment of patient outcomes.

The physician's overall assessment indicated that $\sim 80 \%$ of patients who had CT added to their ongoing pharmacotherapy were stable or improved. A large number of different global severity/status scales have been employed in assessing effects of treatment in patients with AD. That most similar to the measure employed in this study is the Clinical Global Impressions of Change, which provides minimal instructions to the rater. ${ }^{22}$ Results from global assessments of the type carried out in this study have also been shown to be well correlated with quantitative measures of cognitive function/ dementia. $^{23}$

The MMSE is the most widely used brief mental status screening instrument, ${ }^{24,25}$ and has been used extensively for evaluation of patients with $\mathrm{AD}$ in both clinical trials and follow-up of patients being managed in routine clinical practice. ${ }^{26-29}$ In order to evaluate the impact of CT on mild-to-moderate $\mathrm{AD}$ in routine practice, comparison with subjects on standard therapy without CT was examined by literature review. This approach permitted comparison of the present results with those from much larger numbers of patients receiving pharmacotherapy for AD. A summary of results from clinical trials and epidemiologic studies published prior to 2005 indicated a decline in MMSE scores of $0.6-4.4$ points per year in different studies. ${ }^{30}$ More recently, a study of 686 patients with mild-to-moderate $\mathrm{AD}$ with $90 \%$ receiving $\mathrm{AD}$-specific medication indicated an annual decline in MMSE scores of 2.4 points per year. ${ }^{31}$ In comparison, the decline in MMSE scores over 15 months in the present study was 0.48 and not statistically significant. It should be noted that there are limitations to the use of the MMSE for assessment of cognitive function, particularly when comparisons are made across studies. The rate of change for MMSE has been shown to be strongly influenced by the baseline score. ${ }^{32,33}$ Other variables, including patient age, duration of $\mathrm{AD}$, and education, have been linked to rate of decline for MMSE scores, but these relationships appear to be weaker and more variable than those for baseline MMSE score. ${ }^{34-40}$ Thus, comparison of results from the present chart review and those from other studies should be undertaken with caution.

Caregiver assessments also indicate that memory and ability to carry out activities of daily living remained stable or improved during therapy with CT. In an assessment of overall memory, $40 \%$ of the caregivers reported somewhat better or much better memory after initiation of CT. 
Functional impairments in AD place the greatest burden on both caregivers and the economy; ${ }^{41}$ and results from several studies have suggested that neuropsychologic test performance is predictive of activities of daily living performance in patients with $\mathrm{AD} .^{42,43}$ Results from observational studies and clinical trials indicate that deterioration in the ability to carry out activities of daily living can be detected among patients with $\mathrm{AD}$ over follow-up periods comparable with that in the present study. ${ }^{44,45}$

Changes in the requirement for psychiatric medications were used as a surrogate measure for effects of CT on neuropsychiatric symptoms. These symptoms are a source of caregiver burden and are associated with increased probability of institutionalization. ${ }^{46}$ Treatment aimed at improving cognition in patients with $\mathrm{AD}$ has also been shown to decrease the severity of neuropsychiatric symptoms. ${ }^{47}$ Results from the record review indicate that medications for psychiatric illness remained stable for most patients during the period of CT.

Results from the chart review indicated the adverse event most often associated with CT was gastrointestinal upset and that this event led to discontinuation in $7.3 \%$ of patients. Most patients $(89.1 \%)$ were titrated to a full $20 \mathrm{~g}$ daily CT dose and maintained at this dose. While the presumed mechanism of action of CT is the induction of ketosis and subsequent provision of ketone bodies as an alternative fuel for neurons, ketone bodies have been shown to have other neuroprotective effects that may be beneficial, not only in AD but also in other neurologic conditions. ${ }^{15}$ However, it is important to note that there have been reports of detrimental effects of caloric restriction and ketogenic diets on neurologic function. ${ }^{48,49}$ However, induction of mild ketosis by $\mathrm{CT}$ does not require restriction of macronutrients, and therefore may not lead to the detrimental effects attributed to ketogenic diets.

One limitation of this study was that the Apolipoprotein E4 (APOE4) carriage status was evaluated and recorded in the medical records of only seven patients (two were APOE4-positive). Prior clinical results for $\mathrm{CT}$ indicated significant efficacy in APOE4-negative but not APOE4positive patients. ${ }^{10,16}$

In conclusion, results from this small chart review study indicate that addition of CT to pharmacotherapy for AD was associated with stable disease or improvement for most patients over a follow-up period of 18.8 months. Addition of CT was also associated with stabilization or improvements in the ability to carry out activities of daily living for most patients and warrants further investigation in a larger study.

\section{Acknowledgment}

The authors acknowledge the contributions of the following investigators to this research: MR Bolouri (Charlotte, NC, USA); DW Crumpacker (Plano, TX, USA); P Fonzetti (White Plains, NY, USA); IJ Goodman (Orlando, FL, USA); L Kim (Ocala, FL, USA); PM Kostoulakos (Neptune, NJ, USA); VN Lipenko (Bedford, TX, USA); J Shi (Phoenix, AZ, USA); and AG Smith (Tampa, FL, USA).

\section{Author contributions}

SDM and JG contributed to the design of the study, participated as study investigators, and participated in writing the manuscript.

\section{Disclosure}

This study was funded by Accera Inc. The sponsor was involved in the study design, data collection, analysis, and interpretation, as well as manuscript preparation and submission. The authors wish to acknowledge the medical writing and editorial support of Robert Rhoades provided by Accera Inc. SDM is a member of the Accera speakers' bureau. JG is a member of the Accera speakers' bureau and national advisory board.

\section{References}

1. Alzheimer's Association. 2012, Alzheimer's disease facts and figures Available from: http://www.alz.org/alzheimers_disease_facts_and_ figures.asp. Accessed April 25, 2011.

2. Alzheimer's Association. Changing the trajectory of Alzheimer's disease: a national imperative, 2010. Available at: http://www.alz.org/ documents_custom/trajectory.pdf. Accessed April 25, 2011.

3. Gauthier S, Scheltens P. Can we do better in developing new drugs for Alzheimer's disease? Alzheimers Dement. 2009;5(6):489-491.

4. Ihl R. Anti-dementia drugs for dementia syndromes - just unkept promises? MMW Fortschr Med. 2006;2:24-26. German.

5. Raina P, Santaguida P, Ismaila A, et al. Effectiveness of cholinesterase inhibitors and memantine for treating dementia: evidence review for a clinical practice guideline. Ann Intern Med. 2008;148(5):379-397.

6. Mosconi L, Brys M, Glodzik-Sobanska L, De Santi S, Rusinek H, de Leon MJ. Early detection of Alzheimer's disease using neuroimaging. Exp Gerontol. 2007;42(1-2):129-138.

7. Reiman EM, Chen K, Alexander GE, et al. Functional brain abnormalities in young adults at genetic risk for late-onset Alzheimer's dementia. Proc Natl Acad Sci U S A. 2004;101(1):284-289.

8. Robinson AM, Williamson DH. Physiological roles of ketone bodies as substrates and signals in mammalian tissues. Physiol Rev. 1980;60(1):143-187.

9. Cunnane S, Nugent S, Roy M, et al. Brain fuel metabolism, aging, and Alzheimer's disease. Nutrition. 2011;27(1):3-20.

10. Henderson ST, Vogel JL, Barr LJ, Garvin F, Jones JJ, Costantini LC. Study of the ketogenic agent AC-1202 in mild to moderate Alzheimer's disease: a randomized, double-blind, placebo-controlled, multicenter trial. Nutr Metab (Lond). 2009;6:31.

11. Veneman T, Mitrakou A, Mokan M, Cryer P, Gerich J. Effect of hyperketonemia and hyperlacticacidemia on symptoms, cognitive dysfunction, and counterregulatory hormone responses during hypoglycemia in normal humans. Diabetes. 1994;43(11): 1311-1317. 
12. Hasselbalch SG, Madsen PL, Hageman LP, et al. Changes in cerebral blood flow and carbohydrate metabolism during acute hyperketonemia. Am J Physiol. 1996;270(5 Pt 1):E746-E751.

13. Kashiwaya Y, Takeshima T, Mori N, Nakashima K, Clarke K, Veech RL. D-beta-hydroxybutyrate protects neurons in models of Alzheimer's and Parkinson's disease. Proc Natl Acad Sci U S A. 2000;97(10):5440-5444.

14. Van der Auwera I, Wera S, Van Leuven F, Henderson ST. A ketogenic diet reduces amyloid beta 40 and 42 in a mouse model of Alzheimer's disease. Nutr Metab (Lond). 2005;2:28.

15. Stafstrom CE, Rho JM. The ketogenic diet as a treatment paradigm for diverse neurological disorders. Front Pharmacol. 2012;3:59.

16. Reger MA, Henderson ST, Hale C, et al. Effects of beta-hydroxybutyrate on cognition in memory-impaired adults. Neurobiol Aging. 2004;25(3): 311-314.

17. Babayan VK. Medium chain triglycerides and structured lipids. Lipids. 1987;22(6):417-420.

18. López-Pousa S, Bermejo-Pareja F, Frank A, Hernández F, León T, Rejas-Gutiérrez J; ECO. The effect of donepezil in comparison with conventional treatment on cognitive functioning and the performance of the patient in a prospective cohort of patients with Alzheimer's disease treated in routine clinical practice in Spain. Rev Neurol. 2010;51(10): 577-588. Spanish.

19. Santoro A, Siviero P, Minicuci N, et al. Effects of donepezil, galantamine and rivastigmine in 938 Italian patients with Alzheimer's disease: a prospective, observational study. CNS Drugs. 2010;24(2): $163-176$.

20. Riepe MW, Kohler J, Horn R. Donepezil in Alzheimer's disease: a clinical observational study evaluating individual treatment response. Curr Med Res Opin. 2007;23(8):1829-1835.

21. Lawton MP, Brody EM. Assessment of older people: selfmaintaining and instrumental activities of daily living. Gerontologist. 1969;9(3):179-186.

22. Reisberg B. Global measures: utility in defining and measuring treatment response in dementia. Int Psychogeriatr. 2007;19(3):421-456.

23. Ashford JW, Kumar V, Barringer M, et al. Assessing Alzheimer severity with a global clinical scale. Int Psychogeriatr. 1992;4(1):55-74.

24. Alzheimer's Research Forum. Neuropsychological tests, 2009, Available from: http://www.alzforum.org/dis/dia/tes/neuropsychological.asp. Accessed April 25, 2011.

25. Cummings JL, McRae T, Zhang R; Donepezil-Sertraline Study Group. Effects of donepezil on neuropsychiatric symptoms in patients with dementia and severe behavioral disorders. Am J Geriatr Psychiatry. 2006;14(7):605-612.

26. Froelich L, Andreasen N, Tsolaki M, et al. Long-term treatment of patients with Alzheimer's disease in primary and secondary care: results from an international survey. Curr Med Res Opin. 2009;25(12): 3059-3068.

27. Feldman HH, Pirttila T, Dartigues JF, et al. Treatment with galantamine and time to nursing home placement in Alzheimer's disease patients with and without cerebrovascular disease. Int J Geriatr Psychiatry. 2009;24(5):479-488.

28. Minthon L, Wallin AK, Eriksson S, Wattmo C, Andreasen N. Longterm rivastigmine treatment in a routine clinical setting. Acta Neurol Scand. 2009;119(3):180-185.

29. Cortes F, Nourhashémi F, Guérin O, et al. Prognosis of Alzheimer's disease today: a two-year prospective study in 686 patients from the REAL-FR Study. Alzheimers Dement. 2008;4(1):22-29.

30. Behl P, Stefurak TL, Black SE. Progress in clinical neurosciences: cognitive markers of progression in Alzheimer's disease. Can J Neurol Sci. 2005;32(2):140-151.
31. Gillette-Guyonnet S, Andrieu S, Nourhashemi F, et al. Long-term progression of Alzheimer's disease in patients under antidementia drugs. Alzheimers Dement. 2011;7(6):579-592.

32. Mendiondo MS, Ashford JW, Kryscio RJ, Schmitt FA. Modelling Mini Mental State Examination changes in Alzheimer's disease. Stat Med. 2000;19(11-12):1607-1616.

33. Han L, Cole M, Bellavance F, McCusker J, Primeau F. Tracking cognitive decline in Alzheimer's disease using the Mini-Mental State Examination: a meta-analysis. Int Psychogeriatr. 2000;12(2):231-247.

34. Ravona-Springer R, Luo X, Schmeidler J, et al. The association of age with rate of cognitive decline in elderly individuals residing in supporting care facilities. Alzheimer Dis Assoc Disord. 2011;25(4):312-316.

35. Pavlik VN, Doody RS, Massman PJ, Chan W. Influence of premorbid IQ and education on progression of Alzheimer's disease. Dement Geriatr Cogn Disord. 2006;22(4):367-377.

36. Fritsch T, McClendon MJ, Smyth KA, et al. Effects of educational attainment on the clinical expression of Alzheimer's disease: results from a research registry. Am JAlzheimers Dis Other Demen. 2001;16(6): 369-376.

37. Doody RS, Massman P, Dunn JK. A method for estimating progression rates in Alzheimer disease. Arch Neurol. 2001;58(3):449-454.

38. Teri L, McCurry SM, Edland SD, Kukull WA, Larson EB. Cognitive decline in Alzheimer's disease: a longitudinal investigation of risk factors for accelerated decline. J Gerontol A Biol Sci Med Sci. 1995;50A(1): M49-M55.

39. Suh GH, Ju YS, Yeon BK, Shah A. A longitudinal study of Alzheimer's disease: rates of cognitive and functional decline. Int $J$ Geriatr Psychiatry. 2004;19(9):817-824

40. Mungas D, Reed BR, Ellis WG, Jagust WJ. The effects of age on rate of progression of Alzheimer disease and dementia with associated cerebrovascular disease. Arch Neurol. 2001;58(8):1243-1247.

41. Ernst RL, Hay JW. The US economic and social costs of Alzheimer's disease revisited. Am J Public Health. 1994;84(8):1261-1264.

42. Evans JD, Heaton RK, Paulsen JS, Palmer BW, Patterson T, Jeste DV. The relationship of neuropsychological abilities to specific domains of functional capacity in older schizophrenia patients. Biol Psychiatry. 2003;53(5):422-430.

43. Burdick DJ, Rosenblatt A, Samus QM, et al. Predictors of functional impairment in residents of assisted-living facilities: the Maryland Assisted Living study. J Gerontol A Biol Sci Med Sci. 2005;60(2): 258-264.

44. Green CR, Mohs RC, Schmeidler J, Aryan M, Davis KL. Functional decline in Alzheimer's disease: a longitudinal study. J Am Geriatr Soc. 1993;41(6):654-661.

45. Farlow MR, Alva G, Meng X, Olin JT. A 25-week, open-label trial investigating rivastigmine transdermal patches with concomitant memantine in mild-to-moderate Alzheimer's disease: a post hoc analysis. Curr Med Res Opin. 2010;26(2):263-269.

46. Benoit M, Robert PH, Staccini P, et al. One-year longitudinal evaluation of neuropsychiatric symptoms in Alzheimer's disease. The REAL.FR Study. J Nutr Health Aging. 2005;9(2):95-99.

47. Trinh NH, Hoblyn J, Mohanty S, Yaffe K. Efficacy of cholinesterase inhibitors in the treatment of neuropsychiatric symptoms and functional impairment in Alzheimer disease: a meta-analysis. JAMA. 2003;289(2):210-216.

48. Maalouf M, Rho JM, Mattson MP. The neuroprotective properties of calorie restriction, the ketogenic diet, and ketone bodies. Brain Res Rev. 2009;59(2):293-315.

49. Balietti M, Giorgetti B, Fattoretti P, et al. Ketogenic diets cause opposing changes in synaptic morphology in CA1 hippocampus and dentate gyrus of late-adult rats. Rejuvenation Res. 2008;11(3):631-640. 
Neuropsychiatric Disease and Treatment

Dovepress

\section{Publish your work in this journal}

Neuropsychiatric Disease and Treatment is an international, peerreviewed journal of clinical therapeutics and pharmacology focusing on concise rapid reporting of clinical or pre-clinical studies on a range of neuropsychiatric and neurological disorders. This journa is indexed on PubMed Central, the 'PsycINFO' database and CAS.

The manuscript management system is completely online and includes a very quick and fair peer-review system, which is all easy to use. Visit http://www.dovepress.com/testimonials.php to read real quotes from published authors.

Submit your manuscript here: http://www.dovepress.com/neuropsychiatric-disease-and-treatment-journal 